\title{
Las oligarquías locales y los mecanismos de exención del servicio de Cortes en la época de Carlos V
}

\author{
Juan M. Carretero Zamora *
}

\begin{abstract}
RESUMEN ABSTRACT
A partir de la información fiscal

According to the fiscal information contenida en los "servicios de contanied in the "servicios de Cortes", el estudio analiza los mecanismos de exención tributaria diseñados por las oligarquias locales de Castilla durante el reinado del emperados Carlos $V$. El pacto entre la monarquia y las oligarquias locales permitió que amplios sectores sociales pudieran eludir el pago de impuestos.

Todo ello benefició a las familias $y$ a los grupos sociales vinculados con las autoridades municipales del reino de Castilla. Cortes", the study analyses the mechanism of the exemption of taxation designed by the local oligarchies of Castilla during the Reign of Emperor Charles $V$. The ageement between the monarchy and the local oligarchies permitted many social sectors to avoid paying taxes. This benefited the families and social groups related to or connected with the municipal authorities of the Kingdom of Castilla.
\end{abstract}

INTRODUCCIÓN: LOS SERVICIOS Y EL PODER MUNICIPAL

Aunque los sistemas de repartimiento y recaudación de los servicios de Cortes estuvieron teóricamente reglados desde las instancias superiores de la administración hacendística castellana (Contaduría Mayor

* Universidad Complutense. Madrid. 
de Cuentas y Escribanía Mayor de Rentas), en la práctica el peso de la gestión recaudadora directa sobre las pecherías recayó en el ámbito competencial de los concejos; esto es, de los grupos sociales que dominaban las instituciones locales. Este fenómeno es capital (como veremos a lo largo de este estudio) para la comprensión de múltiples aspectos de la compleja vida fiscal castellana y -es ahora lo que nos interesa- profundizar en una circunstancia esencial: cómo las oligarquías locales (responsables en última instancia de la gestión de los impuestos) utilizaron su estatuto en los gobiernos municipales para obtener la exención tributaria tanto en la esfera personal, como en los ámbitos familiares y clientelares.

En el caso de los servicios otorgados por las Cortes, ello es quizá más evidente desde el momento que la asamblea representativa de Castilla fue proyección (tanto por su composición social, como por la defensa de intereses específicos) de la organización y visión de las oligarquías municipales. Estas no sólo tuvieron la capacidad de negociación con la monarquia para establecer los cupos fiscales que correspondían a cada jurisdicción fiscal (provincia, partido, ciudad y lugar), sino que, parapetadas por el poder municipal (ericargado de la gestión y percepción última del servicio) y beneficiarias de las angustias y estrecheces hacendísticas que siempre soportó el emperador (que antepuso siempre el rendimiento fiscal inmediato a los principios de equidad contributiva), pudieron obrar a su más completo albedrío, logrando la exención total o parcial para ellas mismas, sus parentelas, sus clientelas... e incluso, buscando la paz social y la adhesión de sus vecinos, de las localidades donde residian y ejercian los poderes político y social.

\section{LAS EXENCIONES DE SERVICIO EN EL NÚCLEO DEL SISTEMA OLIGÁRQUICO}

A partir de esta realidad, las oligarquías locales castellanas establecieron eficaces mecanismos para obviar las cargas fiscales que hubieran podido mermar sus rentas $y$, muy particularmente, socavar la integridad de sus patrimonios, toda vez, como veremos, que con frecuencia el poder politico se complementaba con la preeminencia económica. En definitiva, las oligarquías locales, al establecer los mecanismos para la distribución de la carga fiscal, aprovecharon su posición dominante para incrementar las rentas particulares desde el momento en que sus bienes patrimoniales - exentos de hecho-- fueron excluidos de la avidez recaudadora de la monarquía. 
Estamos, pues, ante un negocio sin riesgo que sólo conocia el beneficio. No es casual que la liquidez monetaria de esta oligarquía le permitiera, incluso, anticipar a la real hacienda el montante del repartimiento de los impuestos; lógicamente a cambio de los correspondientes intereses sobre el capital invertido en la operación, u otras compensaciones de la más variada naturaleza. La existencia de relaciones de prestamistas «que se ofrecian» a anticipar los impuestos (sobre todo el servicio, porque su recuperación estaba asegurada al ser ellos mismos los recaudadores), viene a confirmar la generalización y reiteración de tales prácticas entre el patriciado urbano ': no sólo no pagaron impuestos, sino que se beneficiaron del sistema fiscal quedándose con una parte del mismo?

La razón última por la que la oligarquía no pagaba los impuestos obedeció a un fenómeno simple, ilegal, aunque definitivo y eficaz: eran regidores u oficiales del concejo. A falta de cualquier otro fundamento jurídico, se diseñó una norma que debía arrastrarse desde tiempo atrás: toda persona con oficio de gobierno era por naturaleza exenta por el mero hecho de ejercerlo. Su reiteración creaba costumbre, esto es, se originó un resquicio legal con el que sustentar tales prácticas ${ }^{3}$.

Aunque las protestas ante estos abusos eran crónicas desde la época de los Reyes Católicos, el panorama resultó ser aún más preocupante cuando empezaron a recibirse en la contaduría mayor los informes de los pesquisidores enviados a realizar las averiguaciones para el reparto del servicio entre los años 1528 y $15322^{4}$. La primera conclusión a la que llegamos es que la exención por oficio de gobierno era prácticamente general en todo el reino, especialmente en los grandes núcleos de población. Sin caer en un análisis casuístico, veamos algunos ejemplos significativos. En la provincia de Córdoba, tanto en lugares de realengo como de señorío, los alcaldes, jurados y otros oficiales

\footnotetext{
Dichas listas, que especifican las localidades, personalidad del prestamista y cantidad adeudada, aparecen en las datas de los servicios de Cortes, y son particularmente minuciosas durante el reinado de Carlos $V$ (especialmente en el periodo 1532-1550).

Estos tipos de préstamos o adelantos oscilaron en torno a una tasa de interés del 4-6 por ciento. En ocasiones (caso del servicio de 1535-1537) alcanzó el 8 por ciento.

El análisis comparado entre los padrones del servicio y la lista de regidores pueden ser definitivamente revelador de este fenómeno. Por nuestra parte, lo hemos efectuado en el caso de la villa de Madrid para el periodo inicial de Carlos V: ningún regidor, aún siendo pechero, consta en tales padrones para el repartimiento del servicio (Archivo de Villa, manuscritos, 59, padrones de 1514,1516 y 1518 ).

4 A.G.S., Contadurias Generales, leg. 768. En adelante citaremos Averiguación.
} 
no pagaban servicio argumentando que la exención tributaria les venía "por servir los dichos oficios» 5 . En Jaén ocurría otro tanto, destacando el caso de Cazorla, donde por costumbre se eximían los alcaldes, regidores y oficiales; un análisis más detenido de este modelo evalúa en 22 el número de oficiales exentos, haciéndose constar que eran «todos pecheros y los más ricos del lugar» ${ }^{6}$. Igual circunstancia se detecta en la mayoría de los lugares de la orden de Calatrava en Andalucía, donde de nuevo se insistía que eran los más ricos los que gozaban del privilegio. En Córdoba, tanto en realengo como en señorío, la exención incluso se extendió a los oficios añales ${ }^{7}$.

Quizá sea Murcia la provincia de la que tenemos una mayor información, quizá por el celo de los pesquisidores enviados por la real hacienda, quizá posiblemente porque en esa jurisdicción el fenómeno de las exenciones alcanzara su dimensión más preocupante. No es que no pagaran los regidores, jurados y sus familias, es que la exención, siempre con el argumento del uso y costumbre, se había extendido a la mayoría de los oficios municipales, incluso los menos relevantes. En Lorca, por ejemplo, se decía que, pese a la protesta de la pechería, no contribuían los regidores, jurados, mayordomo, escribanos... y porteros. En Chinchilla y Hellín se insistía que los oficiales no pagaban servicio "sin título justo" " , extendiendo la exención a familiares y amigos: "porque los oficiales que son de concejo son sus parientes y amigos, o parientes de parientes, o amigos de amigos", y concluia el informe de los pesquisidores: «los poderosos se han quedado con todo". Este mismo problema se detecta en los lugares de señorío, sobre todo en los territorios murcianos de la orden de Santiago; allí, con el pretexto de la existencia de una ley capitular, los oficiales no contribuian en servicios, alcabalas y otras contribuciones.

Sin embargo, el problema fundamental (con serlo) no era si los oficiales se exentaban del pago de impuesto; lo importante -porque afectó al grueso de las oligarquías - eran los criterios que desde los concejos se utilizaron para el reparto de la carga impositiva. $Y$ en este punto el acuerdo entre gobierno y oligarquias locales fue absoluto en la consecución de un objetivo: lograr que los servicios no afectaran a los patrimonios, obviando las leyes que de manera taxativa obligaban a que el impuesto

\footnotetext{
Ibidem, provincia de Córdoba, adiciones. Ibidem, provincia de Jaén, adiciones. Ibidem, provincia de Córdoba, adiciones. Ibidem, provincia de Murcia, adiciones.
} 
fuera proporcional con la capacidad patrimonial de cada individuo. Ello fue posible - como se ha señalado_ porque la capacidad de adscripción del impuesto en relación con los patrimonios había sido delegada en la práctica por la real hacienda en las autoridades locales. Fueron, pues, los regidores los que establecieron los criterios de reparto y las características y límites de las cáñamas, esto es, el diseño de los tramos fiscales en función de las rentas y patrimonios.

Todo ello condujo a que los repartimientos de los servicios los realizaran los más ricos, siempre en función de sus intereses personales y con el objetivo de distribuir el impuesto por vecindades (sin tener en cuenta si el pechero era rico o pobre) sin referencia a las situaciones patrimoniales personales. El informe sobre cómo se procedía en Chinchilla puede ser significativo de una realidad que se reiteraba en la mayoría de las provincias y partidos fiscales castellanos:

"[los ricos] gozan y se aprovechan de todo el término y no pagan cas nada... [porque] los oficios del concejo siempre están en los más ricos y principales, y hácense los repartimientos por mano de los más ricos y oficiales, mayormente los servicios que los hacen los mismos oficiales como les parece, y no como deben ni conforme a justicia" ${ }^{9}$.

Que el servicio estuvo en manos de las oligarquías locales no cabe duda alguna; la documentación es reiterativa hasta la saciedad, lo que viene a confirmar lo generalizado del fenómeno; como también lo fue la anuencia de la hacienda, sólo preocupada por el resultado final del sistema. En la provincia de Castilla de la orden de Santiago los repartimientos fueron ejecutados por el alcalde mayor de la orden, dando lugar a frecuentes enfrentamientos con los pecheros de su jurisdicción ${ }^{10}$; idénticas conclusiones hemos obtenido, entre otras, en los partidos de la

\footnotetext{
Ibidem, informe de los pesquisidores de ia provincia de Murcia. En la mayoría de los lugares de esta provincia los servicios eran repartidos por los oficiales del concejo, o se nombraban diputados para el repartimiento a los más ricos del lugar. Estos se protegían entre sí, aliviándose del pago del servicio al repartirse siempre por debajo del valor real de las haciendas y rentas.

Los pesquisidores, ante la magnitud de los abusos, propusieron que el repartimiento se hiciera en función exclusiva de las haciendas, cargándose un tanto al millar: "así pagarán los ricos por ricos y los pobres por pobres", y que al hacer "los repartimientos se nombre en cada lugar seis personas que sean dos de los ricos, dos de los medianos y dos de los pobres".

10 Fueron especialmente conflictivos los años de la década 1540-1550, cuando gran parte de la jurisdicción requirió la intervención de la contaduria mayor ante los abusos del alcalde mayor.
} 
Mesa Arzobispal de Toledo ${ }^{11}$, Jaén ${ }^{12}$, orden de Calatrava de Andalucía ${ }^{13}$, etc.

No obstante, donde las oligarquías locales proyectaron su poder en el control de los repartimientos fue en la definición del sistema de cáñamas, mecanismo básico para la racionalización del sistema tributario al relacionar la carga fiscal soportada por cada pechero con sus bienes y rentas disponibles. La estrategia observada por las oligarquías fue muy clara: establecer topes contributivos máximos los más bajos posibles con la finalidad de que la fiscalidad sólo afectara a una parte mínima de las rentas y patrimonios, liberando de cualquier prestación el grueso de los mismos; o bien, distribuyendo la masa fiscal en dos conceptos diferentes: un porcentaje por vecindad (sin tener en cuenta la renta) y otro por patrimonio. En cualquiera de los casos, la gran beneficiaria fue la oligarquía que, al ostentar el poder político, pudo diseñar las cáñamas en función de sus apetencias personales.

El sistema más eficaz y de mejores resultados consistió, como he señalado, en constituir un tope máximo de contribución fiscal a partir del cual las rentas y patrimonios eran libres y exentos; el abuso estaba, pues, servido y, además, se presentaba como algo con visos de legalidad, en tanto decisión política de los concejos y de su autonomía en materia fiscal ${ }^{14}$. Por los datos disponibles, podemos afirmar que existió la tendencia a establecer un tope en torno a los 80.000 maravedies de hacienda como cáñama máxima, caso de Jaén ${ }^{15}$, provincia de León de

\footnotetext{
Averiguación, adiciones, repartimiento de Talavera de la Reina y su tierra, donde el repartimiento estaba en manos de los caballeros y oficiales, que distribuian el servicio a su antojo con el argumento de que era costumbre y privilegio de la Hermandad Vieja.

12 ibidem, partido de Jaén. En Jaén, Ubeda y otros grandes núcleos se repartía el servicio por parroquias, vecino por vecino, sin tener en cuenta las haciendas de cada uno de ellos: «... y habiendo respecto a sus haciendas, y tratos y caudales habian de pagar el doble los unos que los otros, por ser los unos pobres y los otros ricos".

${ }_{13}$ El repartimiento lo realizaba el gobernador del partido por vecinos sin tener en cuenta las haciendas, los tratos y los caudales de cada pechero. Hemos detectado protestas de la mayoria de las localidades de la jurisdicción; más en concreto las de Higuera de Martos, Santiago, Jamilena, Lopera, Torres, Jimena, Higuera de Arjona, Barrio de Canena, Bélmez y su tierra y Villafranca.

14 En este sentido, no debemos olvidar que, aunque la legislación fiscal del periodo 1520 1530 exigia la observancia de cáñamas justas, en la práctica los concejos tuvieron plena autonomía en sus decisiones fiscales desde el momento en el que Carlos $V$, acuciado por la necesidad de ingresos inmediatos, autorizó a los concejos a que establecieran los medios que creyeran más oportunos para recaudar los servicios. Desde ese momento, las oligarquías contaron con un respaldo legal para sus arbitrariedades del que hasta entonces habian carecido.

15 Averiguación, partido de Jaén, adiciones. En muchos lugares de esta provincia se estableció que no pechasen a partir de dicha cantidad «porque dicen que lo tienen así de costumbre antigua".
} 
la orden de Santiago ${ }^{16}$ y en los lugares de esta orden situados en Murcia, donde se señalaba que: «el que tiene dos o tres cuentos paga no más de ello que paga el que tiene 80.000 maravedíes". En otras jurisdicciones los topes máximos aún fueron menores; en Alcaraz se estableció que los vecinos ricos no pagasen más allá de los 60.000 maravedíes y en la Mesa Arzobispal fue excepcional pagar por encima de los 25.000. Dentro de esta jurisdicción conocemos con cierto detalle el caso de los lugares de la tierra de Talavera, donde se estableció que el servicio se pagase de la siguiente manera: un tercio por vecindades («tanto al rico como al pobre") y los dos tercios restantes por haciendas, pero con la importante salvedad de que "haciendo hasta en 25.000 maravedies de hacienda pechero mayor, y de allí abajo por sus millares a cada uno según tiene, y de allí arriba huelga y no paga" 17. En Madrid, por citar un último ejemplo, el servicio se repartía a partes iguales por vecindades y haciendas, aunque para estas últimas se establecieron topes máximos contributivos entre 90.000 y 60.000 maravedíes y "si tiene dende arriba, aunque sean 500.000 , no pecha más".

Este sistema de cupo porcentual entre vecindades y haciendas fue muy frecuente en la meseta norte y, sobre todo, en la provincia de Segovia. Los pesquisidores de esa jurisdicción fiscal afirmaron que era muy frecuente que se repartiera el servicio por mitades: una por cabezas («iguales tanto al pobre como al rico") y la otra mitad por haciendas. Sin embargo, las oligarquías manipularon con frecuencia el sistema disminuyendo la propiedad sometida a tributación. Por ejemplo, en Cuevas de Provanco, jurisdicción del conde de Miranda, no se incluyeron entre las propiedades las tierras y las viñas (sólo los bienes muebles y semovientes) ${ }^{18}$. En otros lugares segovianos se interpretó que los ganados no constituian propiedad sometida al pago de los servicios (lo que es muy significativo del éxito logrado por las oligarquías al obtener la exención del bien más importante de sus patrimonios).

En Zamora (Tierra del Vino) se tasaban los bienes muebles y raices; en otros lugares de ese partido se establecían cáñamas de ocho millares con un tope máximo de dos cáñamas (esto es, 16.000 maravedies): "Y los que llegan a los dichos 16 millares, aunque tengan más en mucha o

16 Ello era posible, según opinión de los concejos, por la existencia de un capítulo de la orden que lo permitía.

17 Averiguación, partido de la Mesa Arzobispal.

18 Desconocemos si esta circunstancia obligó a las pesquisidores a bajar la contribución de esta vilia. Fue propuesto un repartimiento anual de 11.000 maravedíes para 71 vecinos pecheros, cuando en el servicio de 1528 había contribuido con 14.460 maravedies. 
poca cantidad, no pagan más de los dichos 16 millares que son dos cáñamas... que es perjuicio de los pobres» ${ }^{19}$. No resulta por ello llamativo que cuando los poderosos veían evaluado todo su patrimonio se entendiera que se estaba cometiendo con ellos un agravio intolerable; los pesquisidores que visitaron la provincia de Segovia tuvieron que oír frecuentes quejas de los hacendados, puesto que "muchos de ellos pagan más de 1.000 maravedíes de servicio cada uno en un año, y otros vecinos pagan ocho maravedies o doce", y señalaron como caso flagrante de injusticia el ejemplo de un pechero que vivía en Aguilafuente (lugar bajo jurisdicción del cabildo de Segovia) que, según estos quejosos hacendados, pagaba la astronómica suma de 5.625 maravedíes de servicio al año ${ }^{20}$.

\section{EXTENSIÓN Y GENERALIZACIÓN DE LAS EXENCIONES: PARIENTES Y CRIADOS. LOS LINAJES}

"Hay muchos vecinos pecheros en los lugares de la provincia de Madrid que se llaman exentos; unos por paniaguados de señores y personas favorecidas, $y$ algunos por paniaguados en la villa de Madrid y su tierra... y otros muchos particulares que son exentos por posesión que tienen de no pechar, y otros por oficios nobles que tienen, así como letrados y escribanos... generalmente los dichos exentos son los más ricos y mejor librados del pueblo" ${ }^{21}$.

Esta frase, incorporada al informe de los pesquisidores que averiguaron las vecindades y posibilidades del repartimiento del servicio de la provincia de Madrid, sintetiza el problema de la extensión del modelo de exenciones fuera del núcleo oligárquico. En efecto, no sólo se benefició del sistema de exenciones la oligarquía propiamente dicha, sino que, como proyección esencial y estructural de la misma, el fenómeno penetró hasta el más ínfimo nivel de dependencia. En definitiva, como en tantos otros aspectos, la fiscalidad (la exención tributaria en este caso) constituyó un poderoso vínculo que favorecía los esquemas de dependencia, en tanto el oligarca hacia partícipe al resto del grupo de los beneficios fiscales obtenidos, siempre en una gradación jerárquica que comprendía desde la parentela más próxima hasta el último de los servidores que, por ejemplo, labraba sus tierras.

\footnotetext{
Averiguación, partido de Zamora, adiciones.

Ibridem, partido de Segovia, adiciones.

Ibidem, provincia de Madrid, adiciones.
} 
De lo que no cabe ninguna duda es que los regidores extendieron la exención de forma mecánica a sus allegados más próximos: familiares, criados y trabajadores de sus explotaciones; el sistema para lograr tales exenciones era eficaz por sencillo: los regidores, al establecer los padrones del servicio, incluía a sus deudos entre la población exenta ${ }^{22}$. En Zamora, ciudad que contó con una poderosa oposición a tales prácticas (la oligarquía cometió, como veremos, algunos asesinatos como medida ejemplarizante para atenuar las denuncias de algunos pecheros inquietos), se llegó a afirmar que los hijos de los regidores no pagaban el servicio porque el privilegio de sus padres también se extendía a ellos ${ }^{23}$.

Una vez eximido el núcleo familiar, el siguiente paso fue amparar a los criados y renteros que trabajaban el patrimonio familiar; de la documentación manejada para todo el siglo XVI cabe inferir la existencia de un doble mecanismo para lograr la exención de tales criados. Uno directo, extendiendo sin más la exención familiar a todos aquéllos que se encontraban vínculados laboralmente con dicho núcleo familiar; otro indirecto y con cierta sutilidad jurídica: si la tierra que labraba el criado o rentero era de una persona exenta, todo lo vinculado a la propiedad seguía el mismo régimen jurídico-fiscal del propietario, o bien la carga fiscal se entendía que correspondía al propietario (que frecuentemente residía en ciudad exenta). Esta es la conclusión a la que hemos llegado tras analizar varios pleitos ante la contaduría mayor durante el periodo 1532-1535 ${ }^{24}$. En este caso se encontraban ciertos caseros de las villas toledanas de Argés, Cobisa, Nambroca y Burguillos que «no pagan servicios porque dicen que son caseros de vecinos de Toledo que tienen allí heredades" 25 .

Esta causa explica la enorme cantidad de exenciones de pecheros detectadas en las jurisdicciones señoriales, singularmente la eclesiástica. Veamos el siguiente cuadro donde constan los lugares que entablaron pleito en defensa de sus pecherías por esta causa concreta de vincular los criados a la propiedad ${ }^{26}$ :

22 Ibidem, partido de Segovia, uporque cada regidor o persona que tiene favor en el regimiento hace meter a sus criados y allegados".

23 "porque los regidores lo mandan asi diciendo que tienen privilegio los dichos regidores para ello".

24 A.G.S., Contadurias Generales, leg. 765, "lugares que no pagaban servicio".

25 Esta situación viene confirmada en las datas del servicio que, cuando se producia un impago, se hacia constar la causa de la suspensión del servicio. Por ejemplo, A.G.S., Contaduría Mayor de Cuentas, 1. época, leg. 1322, servicio extraordinario de 1539, entre otras referencias documentales que podríamos citar.

26 A.G.S., Contadurias Generales, leg. 765 


\begin{tabular}{lll}
\hline Localidad & Partido & Propietario \\
\hline S. Andrés del Arroyo & Palencia & Monasterio de S. Isidro de Dueñas ${ }^{27}$ \\
Berzosa de los Hidalgos & Palencia & Monasterio de S. Isidro de Dueñas ${ }^{28}$ \\
Quintos & Sevilla & Marqués de Tarifa ${ }^{29}$ \\
"Hortexica" & Sevilla & Licenciado Alonso de Céspedes \\
S. Miguel de las Dueñas & Ponferrada & Monasterio de S. Miguel ${ }^{30}$ \\
Tremor de Arriba & Ponferrada & Monasterio de Santa María Magdalena de Cerezal ${ }^{31}$ \\
Santa María de Huerta & Soria & Monasterio de Santa María ${ }^{32}$ \\
Vidayanes & Zamora & Orden de San Juan ${ }^{33}$ \\
\hline
\end{tabular}

La relación de localidades que pleitearon sería interminable; sin embargo, sólo hemos incluido aquéllas en las que expresamente consta esta causa como origen del pleito. Hemos de sospechar que el fenómeno debió adquirir enormes dimensiones (más de 250 casos para el periodo 1532 1535), ya que la mayoría de los pleitos aludian genéricamente a "uso y costumbre". De lo que no cabe duda es que para los propietarios este mecanismo fue de enorme eficacia para atraer a renteros al ofrecerles como aliciente la exención de servicio. De hecho, una estrategia frecuentemente utilizada por los propietarios era la de establecer arrendamientos de corta duración con el objeto de no levantar sospechas ante la real hacienda, evitando que con el paso del tiempo los renteros adquirieran la vecindad. Esto era lo que hacia Cristóbal de Plazuela, propietario del término de Carcelén (Murcia), donde jamás se había pagado ni alcabala, ni servicio, ni otro cualquier impuesto, que tenía la costumbre de que los renteros - al cumplir los tres años de arrendamiento- abandonaran la localidad, siendo inmediatamente sustituidos por otros.

No obstante, donde el fenómeno clientelar se hizo más evidente en el ámbito de la exenciones fue en aquéllas ciudades organizadas en torno al

2. El monasterio pleiteó durante décadas por sus criados; logró la exención definitiva a fines del siglo xvı. De hecho en el vecindario de 1591 consta con el servicio suspendido definitivamente.

28 Idem anterior.

2a Los criados estaban exentos de servicio porque todo era del señor. Esta villa se despobló en la segunda mitad del siglo xvI.

30 Era un monasterio de la orden de San Bernardo. Al requerirse su situación por los contadores mayores, los pecheros alegaron que eran vasallos del monasterio. El prior inició el pleito en 1532 y logró la exención de sus vasallos. A fines del siglo xvI consolidaron la exencióri de servicio y milones.

31 El monasterio tenía el privilegio de exentar a 10 criados. Fue requerido por la real hacienda y el monasterio hizo alegaciones en 1532, aunque desconocemos el resultado final del pleito.

32 Los vasallos fueron defendidos por el mayordomo Alonso Fernández en representación de la orden de San Bernardo. El pleito fue ganado por la orden (A.G.S., Contaduría Generales, proviricia de Soria, adiciones).

${ }_{33}$ Los 60 vecinos pecheros carecian de bienes y toda la renta pertenecía al comendador. 
sistema de linajes. Por desgracia las fuentes fiscales son poco explícitas y sistemáticamente silencian el problema; por fortuna ese silencio fue roto por los pesquisidores Juan de Figueroa y Jerónimo de Solís que, encargados de la averiguación de la ciudad de Segovia, realizaron un informe demoledor sobre los abusos cometidos por los linajes segovianos de D. Dia Sanz de Quesada y D. Fernando García ${ }^{34}$. Estos linajes fundamentaban sus privilegios fiscales a partir de hipotéticos servicios a la monarquia de orden militar; en la realidad se habian transformado en una gigantesca máquina de exenciones tributarias que beneficiaban a la generalidad de la pechería segoviana: "de la forma que ahora se usa - significaban los pesquisidores- es cosa de disparate».

En efecto, al calor de los linajes se habían ido acercando todo una serie de oficiales de los gremios, menestrales, criados, allegados, parientes... incluso, para escándalo de la hacienda, los que ejercian oficios mecánicos; y lo más grave era que, una vez admitidos en los linajes, adquirian la condición de hidalgos ${ }^{35}$. El mecanismo de inclusión, a los ojos de los pesquisidores, era muy sencillo: los regidores y las personas con influencia en el concejo incluian en los linajes a sus familiares y paniaguados, elevándose el número de exentos a 1.013 personas; quiza sea una apreciación excesiva, pero en cualquier caso muy significativa de la eficacia de los linajes:

"No pagan cosa alguna porque tienen su tabla de carne a parte franca de la dicha sisa, todo sobre los otros vecinos; y lo que es peor: es que muchas personas sirven a las justicias y regidores porque los hagan meter en los dichos linajes, y después que los han metido, cada que se les antoja, los qui$\tan y$ meten otros de nuevo. $Y$ al presente están en los dichos linajes 1.013 personas, con hijos y criados, casados y no casados...".

\section{EXTENSIÓN Y GENERALIZACIÓN DE LAS EXENCIONES: OTRAS EXENCIONES. LA HIDALGUÍA Y EL RÉGIMEN SEÑORIAL}

Dentro de los ámbitos urbanos de la Castilla del siglo XVI fue muy frecuente la existencia de ciertos grupos profesionales - casi siempre imbricados de manera directa o indirecta con las oligarquias- que se beneficiaron de los privilegios de exención de servicios con la anuencia explícita

34 A.G.S., Contadurias Generales, leg. 768, fol. 375. "Adiciones de las cosas que resultan de la averiguación de la provincia de Segovia que ticieron y averiguaron Juan de Figueroa y Jerónimo de Solís".

35 Ibidem, "... y si no se remediase, muchos se podrían hacer hidalgos no lo siendo". 
de las autoridades municipales. Ello se explica porque dichos grupos profesionales estaban participados por las mismas familias de las oligarquías, afectaban a sus redes clientelares o prestaban servicios a los grupos dirigentes. Aún más, su situación de privilegio fiscal sólo es comprensible porque los concejos, desde tiempo inmemorial (casi siempre pretextaron derechos consolidados por la costumbre), no los incluyeron en los correspondientes padrones fiscales. Además, como es bien sabido, la conformación de las oligarquías castellanas desde el siglo xv no fue ajena a frecuentes estrategias matrimoniales con familias vinculadas a ciertos oficios (caso, como ejemplos significativos, de los monederos y oficiales de atarazanas).

La averiguación ordenada por Carlos $V$ es significativa en sus conclusiones sobre este fenómeno, especialmente en los grandes núcleos castellanos y andaluces. De los primeros, el caso más explícito lo constituye el de la ciudad de Segovia, cuyos oficiales de la casa de la moneda gozaban de amplísimas exenciones fiscales ${ }^{36}$, dando lugar a un modelo de abuso y corruptela generales. En Segovia se producía, como en el resto de Castilla, el fenómeno del incremento artificial del número de monederos (la mayoría de los cuales ni ejercían el oficio), extendían la exención a sus viudas ${ }^{37} \mathrm{y}$, sobre todo, que, al calor de las exenciones, toda una serie de mercaderes y ricos negociantes habian comprados los oficios precisamente para no pagar impuestos: "porque son oficiales de otros oficios de mayor interés, y otros son ricos mercaderes y tratantes que están ocupados en sus negocios... hay muchos monederos muy ricos y que sólamente compran y procuran haber los dichos oficios por gozar de la libertad" ${ }^{38}$. En Sevilla la situación era análoga tanto para monederos como para los oficiales de los alcázares reales y las atarazanas ${ }^{39}$.

Además de este tipo de oficios, los concejos solían exentar los que denominaban "oficios nobles", esto es, en el caso de Madrid, los letrados y los escribanos. En la provincia de Segovia estaba muy extendida la costumbre de que fueran los propios concejos los que eximieran a determinados oficios, siempre con la condición de que los ejercieran de manera efectiva:

${ }^{36}$ Averiguación, provincia de Segovia, adiciones.

37 Ibidem, "...hay al presente 91 monederos y muchas mujeres viudas que, por haber sido casadas con monederos, gozan todavia de la libertad de sus maridos, y de estos 91 monederos pocos de ellos sirven, porque no hay necesidad".

38 Ibidem. El subrayado es nuestro.

39 Averiguación. El informe de los pesquisidores de Sevilla es coincidente con el de Segovia: la mayoría de los oficiales no ejercían los oficios y los mantenían ficticiamente para exentarse ellos mismos y sus familias. 
"en la provincia de Segovia hay otros muchos exentos, asi como boticarios, barberos, herreros, mesegueros, hospitaleros y pregoneros, que en muchas partes los exentan los concejos porque sirvan los dichos oficios" ${ }^{40}$.

La casuística de este fenómeno es enorme, rebasando ampliamente las posibilidades formales de este trabajo; valga como otro ejemplo significativo, la tendencia de las oligarquías y de los privilegiados a primar fiscalmente ciertos oficios como el de sepultureros, exentos por enterrar a dichos grupos sociales (Ávila).

El fenómeno de la exención de servicios por hidalguía constituye en sí mismo un verdadero universo por su extensión y complejidad en el análisis de sus causas. Sin embargo, hay una realidad que no debe soslayarse: en muchos casos fueron las autoridades municipales y los grupos dirigentes los más interesados en defender dichas exenciones, sin duda porque la verdadera evaluación de la situación de ciertas hidalguías por la real hacienda podría haberse llevado por delante las mismas exenciones de las que gozaban las oligarquias locales; prefirieron, pues, defender el sistema en su conjunto antes que verse complicados en un proceso de clarificación del que quizá fueron los primeros perjudicados.

Por desgracia, de los cientos de casos análizados a través de la documentación producida por los servicios, sólo algunas decenas son explícitas en el problema que nos ocupa; esto es, la plena implicación de las oligarquías que ostentaban el poder municipal en los mecanismos de exención tributaria. Ahora bien, que los concejos (sobre todo de Asturias y Trasmiera) eran responsables de la eficacia de «la máquina de producir hidalguías" no cabe la menor duda; la propia real hacienda, sabedora de la corruptela, no cejó de amenazar a los grupos dirigentes locales con repartirles a ellos la carga fiscal si persistían en ocultar población pechera, o en adscribir caprichosamente a la misma situaciones jurídicas de privilegio que no le correspondían ${ }^{41}$.

40 En el caso concreto de Cuéllar, cuya documentación es más precisa, se evaluaron en 4 el número de pregoneros exentados por el concejo, aunque la exención sólo estaba vigente en tanto sirvieran el oficio.

El fenómeno era crónico. Ya en las averiguaciones iniciadas a partir de 1528 los pesquisidores informaron de la connivencia de los concejos y los falsos hidalgos (Averiguación, provincia de León, partido de Asturias de Oviedo y provincia de Burgos, partidos de las Cuatro Villas y Trasmiera). Asimismo, en repartimientos de servicios posteriores de la época de Carlos V; por ejemplo los correspondientes a los servicios de 1535 a 1537 (A.G.S., Escribanía Mayor de Rentas, leg. 287) y 1539 a 1548 (A.G.S., Contaduria Mayor de Cuentas, 1. época, leg. 1322); también durante todos los servicios del reinado de Felipe $1 /$ (caso, entre otros, de los servicios de 1570 a 1578, en A.G.S., Contaduria Mayor de Cuentas, 2. época, leg. 346) 
En el partido de las Asturias de Oviedo (un modelo sobre el que poseemos cierta información) eran los propios concejos los que favorecieron la existencia de exentos; la ciudad de Oviedo, que gozaba del privilegio de exentar a todos sus vecinos, se convirtió en un polo de atracción de pecheros de los lugares próximos. La artimaña utilizada era sencilla y eficaz: los regidores de la ciudad incorporaban a los padrones del servicio a todos sus paniaguados, aunque la mayoría no residian en la localidad, siendo casi siempre los más ricos de los lugares: "éstos son los más ricos de los dichos concejos, y de esto se agravian mucho los otros, porque pagan por los que asi se avecindan en la dicha ciudad" "42. Cuando en algún concejo, especialmente estricto con las hidalguias, se negaba a tales prácticas corruptas, los pecheros tenían un último recurso: interponer pleito ante el corregidor, que sistemáticamente nombraba hidalgo al pechero pleiteante:

"de esto se agravian los concejos, porque de esta manera todos se hacen hidalgos; que por diez años que está uno que no paga a causa de alguna persona que le excusa, dice que está en posesión de no pagar, aunque le conocen los padres pecheros".

Veamos la siguiente relación donde constan tan sólo aquellos concejos que manifestaron estar todos poblados por hidalgos, aunque como vemos en la última columna constaban la existencia de población pechera:

\begin{tabular}{lcc}
\hline Localidad & MRS. Repartidos & Vecinos Pecheros \\
\hline Riosa & 1.500 & 35 \\
La Ribera $^{43}$ & 3.000 & 75 \\
Coto de Villoria $^{44}$ & 2.500 & 60 \\
Villanueva de Oscos $^{45}$ & - & 60 \\
\hline
\end{tabular}

Más en concreto, A.M. de Santander, A $n^{0} 4$, expt. 33, donde de manda que ciertos lugares -que se dicen exentos diciendo que nunca pagaron por ser todos los vecinos hidalgos- hagan los correspondientes padrones «so pena que las dichas justicias pagarán todo lo que monta el servicio", con el apercibimiento que, a su costa, serían enviadas personas de la corte para realizar los padrones y percibir el servicio.

${ }_{42}$ Averiguación, provincia de León, partido de las Asturias de Oviedo, adiciones

43 Era jurisdicción del obispo de Oviedo. Los pesquisidores hicieron constar que a fines del siglo $x \vee$ pagaban servicio.

44 Jurisdicción de Iván Bernal.

45 Pertenecía al monasterio de Santa María y los pecheros se encontraban bajo protección del obispo: «nunca lo pagaron [el servicio], ni se sabe que en el hay pecheros, porque nunca los empadronaron". Consta que tampoco pagaban alcabala. 


\begin{tabular}{|c|c|c|}
\hline Localidad & MRS. Repartidos & Vecinos Pecheros \\
\hline La Mortera ${ }^{46}$ & 2.000 & 20 \\
\hline Villavaler ${ }^{47}$ & - & 40 \\
\hline Morcín ${ }^{48}$ & - & 100 \\
\hline Llanera 49 & 7.200 & 300 \\
\hline Carrandi 50 & 700 & 27 \\
\hline Paderní y Marentes & 1.000 & 26 \\
\hline Tornin ${ }^{51}$ & - & 15 \\
\hline Cabranes 52 & 5.200 & 160 \\
\hline Poreño & 800 & 20 \\
\hline Piañez & - & -53 \\
\hline
\end{tabular}

En Trasmiera la hidalguía general ya era un hecho consolidado a principios del siglo XVI pese a que los informes de la real hacienda demostraban la existencia de poblaciones pecheras ${ }^{54}$. En la Junta de Parayas (Ojebar, Rasines, Gibaja y Ramales de la Victoria) se evaluaron 500 vecinos y en los valles de Soba y Ruesga otros mil más, aunque no se diferenciaba entre pecheros e hidalgos. Por algunos padrones de servicio de la época de Felipe II (donde se hace constar la existencia de hidalgos, pecheros y "dubdosos") puede inferirse que la población pechera no era menor del 20 por ciento.

En las jurisdicciones señoriales hemos observado que todos los asuntos relacionados con el repartimiento y percepción de los servicios recayeron en las autoridades municipales; de hecho, la documentación sobre

46 Estaba incluida en el concejo de Tineo y su jurisdicción pertenecía a Juan Garcia de Tineo; no pagaba servicio ni alcabala. En el recuento de 1591 toda su población se tenía por hidalga.

47 En el concejo de Pravia y jurisdicción del licenciado de Arango. Decian que todos eran hidalgos, aunque era una afirmación absolutamente falsa; parece ser que imponían fuerzas a los que intentaron evaluar la población pechera: nadie «osa empadronarios".

48. Jurisdicción del obispo de Oviedo. Aunque existía un padrón-hita de la pecheria, "todos están por hidalgos". Pleitearon durante el siglo xvi y en 1591 aún mantenian el pleito vivo ante la real hacienda (esto es, seguian sin pagar cualquier impuesto).

49 Jurisdicción del obispo de Oviedo: “Todos están en posesión de hidalgos, y que si hay algún pechero no se puede saber... y que oyeron decir que algunos hay en el dicho concejo que son de linaje de pecheros, y que los que dicen que son pecheros, que son más de 50 ".

50 Concejo de Colunga, jurisdicción del obispo de Oviedo: “los más de ellos son pecheros, y que los que viven en el coto andan con los hidalgos".

51 Jurisdicción de Juan de Caso, personaje principal del partido. Habia 15 vecinos que "no se sabe si son pecheros". A fines de siglo todos los vecinos constaban como hidalgos.

52 "que asimismo en el dicho concejo hay algunos hijos bastardos, e hijos de clérigos y otras personas que podrian ser pecheros"

53 Jurisdicción de la abadía de San Vicente de Oviedo. No pagaban servicio aunque vivían bastantes pecheros.

54 A.G.S., Contadurias Generales, leg. 765. Para toda la Trasmiera consta un apunte de 2.000 vecinos; para la Liébana, 1.300; para el valle de Toranzo 900 privilegiados y 29 pecheros, etc. 
este aspecto que se conserva en los fondos señoriales es prácticamente nula; lo cual no implica que los señores (sobre todo los eclesiásticos) no fueran beligerantes a la hora de lograr beneficios fiscales en sus jurisdicciones a través de obtener un coeficiente maravedi/pechero más bajo que en los realengos, o bien obtener simplemente la exención completa de los vecinos asentados en sus jurisdicciones. $Y$, sobre todo, apoyaron a las oligarquías locales en los numerosos pleitos que ante la real hacienda se interpusieron con la finalidad de lograr la ansiada exención tributaria.

Ya hemos observado, al analizar el caso de algunos concejos asturianos, que la mayoría de estos lugares pertenecían a jurisdicciones señoriales eclesiásticas y que gozaron de la protección del obispado ovetense y de los monasterios. Cuando a partir de 1532, a la vista de los informes de los pesquisidores, la contaduría mayor inició el proceso de requerimiento a los lugares que no pagaban servicio, la reacción de los concejos bajo jurisdicción señorial fue inmediata: alcaldes mayores de órdenes militares, mayordomos de señoríos y regidores de los concejos, siempre a la sombra protectora de los titulares, respondieron con una serie de pleitos en defensa de pretendidos privilegios de exención que abarcaron cronológicamente todo el siglo XVI. El objetivo perseguido por la oligarquías y los señores era obvio: favorecer fiscalmente a sus pecheros, intentado convertir los señorios en verdaderos paraísos fiscales frente a la hacienda de la monarquía.

El condestable de Castilla alegó sin éxito por Briviesca y Belorado, pudo sostener a base de pleitos las exenciones de servicio de Frías e Itero de Castillo y logró que se suscribieran sus tesis en el caso de Castilnovo y su tierra ; el conde de Benavente también apoyó ciertos pleitos bajo el pretexto (de enorme debilidad jurídica) de que si sus vasallos pagaban el servicio se despoblarían parte de sus estados ${ }^{55}$, o bien que el servicio al rey había sido sustituido por ciertas prestaciones señoriales; las órdenes de Santiago y San Juan apoyaron a sus pecheros con el argumento que la exención de servicio estaba contemplada en los privilegios concedidos antiguamente por la monarquía a la orden; etc. Sin embargo, donde la reacción señorial alcanzó mayor unanimidad fue en Guadalajara $y$, sobre todo, en Andalucia.

En Guadalajara ${ }^{56}$ fueron requeridos el duque de Infantado, el marqués de Mondéjar, los condes de Salinas y Coruña, la ciudad de Guadalajara, el

55 Caso de Sanabria y Portillo.

Sobre estas exenciones de servicio de Guadalajara, J.M. CARRETERO ZAMORA, “Fiscalidad y presión fiscal en La Mancha durante el reinado de Carlos I (1519-1554): el servicio ordinario y extraordinario", en Cuadernos de Estudios Manchegos, 21, especialmente las páginas 45-52. 
monasterios de Sopetrán, Villaviciosa y Vallehermoso, así como otros senores seculares sin título: un total de 25 localidades, de las que sólo se obtuvo la exención completa en los casos de Fresno de Torote, Serracines, Vallehermoso de las Monjas, Buitrago, San Pedro de Palmiches y Cañamares (jurisdicción de Luís Carrillo). La pobreza de los resultados judiciales obedeció a la endeblez de los argumentos utilizados (uso y costumbre de no pagar servicio), así como a que en la mayoría de los casos los concejos, al ser requeridos por la real hacienda, ni siquiera tuvieron fuerza jurídica para alegar.

No ocurrió lo mismo en Andalucia, donde el requerimiento fue alegado por la casi totalidad de los concejos y señores jurisdiccionales; otro cosa muy diferente fue el resultado de los pleitos, casi todos desfavorables a las tesis de los pleiteantes ${ }^{57}$, ya que en la mayoría de los casos las exenciones tributarias eran temporales como consecuencia de nuevos poblamientos. Veamos el siguiente cuadro:

\begin{tabular}{lrll}
\hline Localidad & Vecinos & Propietario & Alegación \\
\hline Castillo de Almenara & 5 & conde de Palma & nunca pagó servicio \\
Torre de Aguayo & 7 & Francisco Aguayo & privilegio \\
Villamartín & 437 & ciudad de Sevilla & propios de Sevilla \\
Villafranca de Marisma & 82 & ciudad de Sevilla & no consta causa \\
Chucena & 43 & D. Pedro Pacheco & privilegio \\
Quintos & 20 & marqués de Tarifa & todo es del marqués \\
Puebla de Cazalla & 252 & conde de Urueña & nuevo poblamiento \\
Ortejicar & 31 & conde de Urueña & nuevo poblamiento \\
Pruna & 38 & duque de Arcos & nuevo poblamiento \\
Puerto Real & 234 & realengo & nuevo poblamiento \\
Quema & 8 & iglesia de Sevilla & nunca pagó servicio \\
Gelo & 15 & Jerónimo de Alcazar & nunca pagó servicio \\
Villafranca del Aljarafe & 5 & Alonso de Céspedes & nuevo poblamiento \\
Tarifa & 713 & marqués de Tarifa & privilegio \\
Ardales & 269 & conde de Teba & nuevo poblamiento \\
Puebla de Campillos & 107 & conde de Teba & nuevo poblamiento \\
Paterna de Ribera & 75 & marqués de Tarifa & nuevo poblamiento \\
Santiago de Barbate & 5 & duque Medinasidonia & peligro de «los moros" \\
"Hortexica" & - & Alonso de Céspedes & heredamiendo s8 \\
\hline
\end{tabular}

Además de estas exenciones generales, el régimen señorial logró que gran parte de los grupos dirigentes de sus concejos obtuvieran la exención

\footnotetext{
57 Sólo lograron la suspensión del servicio las localidades de Puerto Real, Quema y Tarifa, en tanto quedaron despobladas a lo largo del siglo xv। Quintos y Villafranca del Aljarafe.

58 Los renteros pagaban el servicio alli donde estaban avecindados.
} 
de servicios, especialmente en ciertos concejos de la provincia de Guadalajara vinculados a la casa del Infantado ${ }^{59}$; pero lo más común fue que los señores, parapetados en su prestigio e influencia sobre los concejos (incluso en los de realengo), posibilitaran que sus criados fueran exonerados del pago de tributos. Por citar un ejemplo de ello, el duque de Alburquerque logró que nueve criados y diez trompetas fueran excluidos del padrón del servicio de Cuéllar; los argumentos eran que los criados poseían la calidad de hidalgos y los trompetas eran libres por ejercer tal oficio; la realidad era muy diferente: nadie del ayuntamiento se atrevía a repartirles por servir al duque, porque «aunque no lo tienen mostrado [los privilegios de exención], ni les piden que los muestren, por contemplación del duque" ${ }^{60}$.

Otra estrategia frecuentemente utilizada por la nobleza era negarse a entregar los padrones de pecheros de sus jurisdicciones ${ }^{61}$, o bien aprovecharse del desconocimiento que la contaduría real tenía de la realidad castellana de principios de xvl; esto es, que los viejos repartimientos del servicio (basados en la situación que el reino poseía a fines del siglo xV) no incluían a determinadas localidades, la mayoría de ellas, no casualmente, bajo régimen señorial. En el partido de Zamora, por ejemplo, algunas jurisdicciones del conde de Benavente ${ }^{62}$ no estaban incluidas en el repartimiento, y los pesquisidores se preguntaban dónde podrían estar dichas localidades: ¿en el partido de las tierras del conde de Benavente?, ¿en Zamora? o ¿quizá en Valladolid? Igual sucedía con el lugar de Otero (jurisdicción del condestable de Castilla) que, con 50 vecinos, tampoco pagaba servicio al no constar oficialmente su existencia; los pesquisidores de Zamora preguntaron si estaba incluido en la provincia de Valladolid. Ante la duda, tomaron la sabia decisión de no andarse por la ramas y repartir 100 maravedies a cada vecino pechero.

En el caso de Soria, también hemos detectado un mecanismo muy eficaz para exentar a las localidades de señorio: aprovechar el cambio de titular de la jurisdicción para hacer desaparecer fiscalmente el lugar o lugares incluidos en el cambio de titularidad. Ello era posible porque la contaduría mayor, al distribuir los servicios en las jurisdicciones señoriales,

\footnotetext{
Averiguación, provincia de Guadalajara.

Ibidem, provincia de Segovia. El subrayado es nuestro.

1 Averiguación, provincia de Trujillo. Alburquerque, jurisdicción del duque de Alburquerque, no dió padrón alegando que la localidad era tradicionalmente libre de servicio. Los pesquisidores, ante la negativa de las autoridades locales, les adscribieron una población de 1.500 vecinos; luego, ante la protesta, se llegó a un pacto: Alburquerque pagaría por 1.090 pecheros.

6.2 Concretamente el lugar de Valleluengo, recientemente poblado y con una población de 15 vecinos. También se cita el lugar de Viadanes, con 60 vecinos. Ambos, lógicamente, al no existir oficialmente para la real hacienda, no pagaban servicio.
} 
sólo atendía al criterio del titular de las mismas; esto es, englobaba en una determinada cantidad a todos los lugares que poseía un señor. Esto explica que cuando las villas de Torrecuadrada y Renales pasaron de la jurisdicción del duque de Medinaceli a la del conde de Cifuentes ambas desaparecieran del repartimiento: al no constar en el ducado de Medinaceli no se las incluyó en la provincia de Soria ${ }^{63}$. En esta misma provincia el conde de Miranda, aunque percibía todos los derechos señoriales del lugar de Castillejo, ocultó la existencia de la jurisdicción hasta que fue descubierta por los pesquisidores que visitaron la provincia.

\section{¿HACIA UNA EXENCIÓN HORIZONTAL? LOS BENEFICIOS DEL MUNDO URBANO}

Si hasta ahora hemos analizado las exenciones surgidas de la estructura organizativa vertical que acompaña a todo sistema oligárquico, convendría reflexionar sobre un aspecto esencial para comprender las estrategias que robustecieron el poder político y el papel social preeminente alcanzados por las oligarquías en su entorno más próximo, allí donde residian; en definitiva, el deseo interesado de los poderes locales de beneficiar fiscalmente a aquellos vecinos sobre los que cotidianamente ejercían su influencia. Esto es, favorecer a las pecherías urbanas frente a las rurales, sobre todo en el caso de ciudades y villas que eran cabecera de extensas y pobladas jurisdicciones y tierras.

Para lograr este objetivo las oligarquías contaron con los enormes recursos de los poderes municipales y, sobre todo, con la capacidad de interpretar a su arbitrio las condiciones que deberian observarse en el reparto "por menudo" de las cantidades adscritas a las villas y sus tierras, y de las que las oligarquías eran responsables de la gestión. A ello cabria añadir la total disponibilidad de las haciendas municipales para establecer sistemas alternativos de pago (recurso a los propios y arbitrios) o sufragar los costosos pleitos, en defensa de las exenciones, ante la contaduría mayor, Chancillerías u otras instancias judiciales.

El primer mecanismo que utilizaron esas oligarquias para obtener la exención general de las pecherías fue el de negarse a entregar los padrones a la real hacienda, bajo el pretexto de que nunca los habían realizado porque la localidad en cuestión gozaba de privilegio, o bien sencilla-

63 Averiguación, provincia de Soria, informe de los pesquisidores. Asimismo, A.G.S., Escribania Mayor de Rentas, leg. 154, repartimiento de los servicios de 1519 a 1533. 
mente porque «nunca nos han pedido que pagásemos el dicho servicio» 64 . Entre los grandes núcleos castellanos que se negaron a entregar padrones estaban: Valladolid que argumentó poseer privilegio de franqueza ${ }^{65}$, Medina del Campo y sus arrabales (franqueza), Medina de Rioseco («nunca hubo padrón»), Simancas entregó un padrón incompleto, Plasencia alegó privilegio, Alcántara no haber pagado nunca, Córdoba incluyó tanto a pecheros como hidalgos, con lo que el padrón fue tenido por inútil por los pesquisidores, etc. Otra argucia muy utilizada consistía en entregar un padrón único que englobaba de forma indiferenciada a la ciudad cabecera y al resto de los lugares de su tierra; de esta estratagema hay innumerables ejemplos, sobre todo en la meseta norte ${ }^{66} \mathrm{y}$ en las jurisdicciones señoriales de Andalucia (caso de las tierras de los duques de Medinasidonia y de Arcos ${ }^{67}$ ).

Un segundo mecanismo que utilizaron las oligarquías y que resultó ser el de mayor eficacia fue el de entablar pleitos interminables con la real hacienda; dicha eficacia se sustentaba en una consecuencia del procedimiento judicial ante los tribunales de hacienda: en tanto el pleito "estaba vivo", la contaduría mayor, en tanto instancia judicial, suspendía el cobro del servicio. De las decenas de localidades que fueron requeridas entre 1532 y 1535 , muchas de ellas si siquiera apelaron, puesto que consiguieron la exención a causa de la hidalguia general; otras, ante la debilidad de su posición jurídica, optaron por el silencio. No obstante, según los datos del servicio de 1536, 65 optaron por interponer

64 Esta situación era frecuente en los lugares nuevamente poblados a partir de fines del XV, $y$ afectaban casi siempre a zonas de señorio. Por citar algún ejemplo, en Córdoba las localidades de Almenara (conde de Palma) y La Torre (Francisco de Aguayo) argumentaron que nunca se les había pedido que pagasen el servicio.

Se trataba, sin duda, de una estratagema del concejo vallisoletano. La ciudad, en efecto, pagaba el servicio, aunque recurriendo al sistema de sisa, por lo que nunca hubo necesidad de elaborar padrones para el pago de servicios. En este sentido, A.M. de Valladolid, caja $2, n^{\circ} 25, « \ldots$ nunca ha habido en esta villa repartimiento de pecheria, y su magestad [se refieren a ciertas provisiones de Carlos $V$ ] algunas veces manda dar, y se han dado, provisiones para echar en sisa lo que se le paga de servicio ordinario... y porque nunca se ha visto, como arriba es dicho, hacerse repartimiento de pecheria los que hoy son vivos".

De hecho, a finales del reinado de Carlos $V$ la ciudad seguia sufragando los servicios mediante sistemas alternativos al repartimiento entre la pecheria, especialmente con las sobras del encabezamiento de alcabalas (Ibidem, tols. 5-8 y 11-14, provisiones de 23 de mayo de 1554 y 7 de agosto de 1555).

56 En este caso se encontraban, por citar algún modelo, gran parte de la tierra de Salamanca, ciertas jurisdicciones de Soria, León, Avila, etc. No fue infrecuente que en un solo padrón se llegase a incluir decenas de localidades (por ejemplo, Rueda del Almirante, cuyo padrón englobó a 39 lugares).

67 Averiguación, provincia de Sevilla, "Repartimiento de lo que han de pagar en los servicios venideros... que van repartidos juntos y se han de dividir lo que cada uno ha de pagar por sí". 
recurso; en 1571 todavía 37 seguían sin pagar servicio ${ }^{68}$ por encontrarse pleiteando.

De todos estos pleitos cabe destacar los que iniciaron las oligarquías en defensa exclusiva del mundo urbano (de muros adentro), especialmente Buitrago, Reina, Fuentidueña y Escalona. Buitrago y Fuentidueña consiguieron sus objetivos, y constan sus servicios suspendidos en 1591; desconocemos qué ocurrió con Escalona, aunque Reina (partido de León de la orden de Santiago) siguió pleiteando hasta 1591 con el argumento de "que son libres de pechar porque tienen de ello privilegio"; al cabo de 59 años la contaduría mayor falló en su contra, y en el servicio de 1591 se les repartió el impuesto "sin perjuicio de cualquier privilegio". No obstante, varias generaciones que vivieron "de muros adentro" lograron eximirse del pago de servicios.

Otra práctica detectada era que cuando alguna villa y su tierra gozaba de un cupo de exentos, dicho cupo era adscrito por las autoridades municipales a la villa en perjuicio de la pechería de la tierra, y más en concreto a los poderosos y más ricos del lugar. La estratagema era de gran eficacia y beneficiaba a toda la pechería del núcleo urbano: al eximirse las haciendas más saneadas de la localidad y hacer recaer el impuesto sobre los pobres (que carecian de patrimonio), el repartimiento global de la villa bajaba; posteriormente el concejo establecía medios de pago satisfactorios para todos (recurso a los propios municipales o establecimiento de una sisa). En este caso se encontraba, por ejemplo, Santa Maria la Real de Nieva ${ }^{69}$; se le evaluó hacia 1530 una vecindad de 447 pecheros, aunque habia un cupo de 250 exentos; el cupo se asignó a los más ricos, con lo que sólo quedaron 197 vecinos sometidos al servicio. Ello permitió que el repartimiento inicial para toda la localidad de 70.000 maravedíes quedase reducido a tan sólo 28.000 .

Sin embargo, donde las oligarquías urbanas obtuvieron sus mayores éxitos en beneficio de la pechería urbana frente a las espectativas del mundo rural fue a través del control y asignación de los repartimientos; ello era posible porque la contaduría mayor asignaba una cantidad global a las villas y sus tierras, y eran las autoridades de la localidad cabecera de la jurisdicción fiscal las que asignaban lo que correspondía pagar a cada uno de los núcleos de su tierra. Los abusos detectados entre 1528 y 1535 alcanzaron dimensiones gigantescas, llevando la preocupación a los contadores mayores.

68 A.G.S., Contaduría Mayor de Cuentas, 2. época, leg. 346. Especialmente las datas del servicio, donde constan las suspensiones por pleito.

59 El informe de la situación de esta villa en Averiguación, provincia de Segovia, adiciones. 
La casuística sería inabarcable para un estudio de estas dimensiones; no obstante, veamos algunos ejemplos significativos del problema.

En toda la provincia de Segovia era muy frecuente - según informe de los pesquisidores- que las ciudades agraviaran a las tierras (caso, por ejemplo de Pedraza y la ciudad de Segovia respecto los sesmos de su tierra); ello queda manifiestamente patente en el siguiente cuadro que refleja las diferencias entre Segovia y su tierra:

\begin{tabular}{lrcc}
\hline Demarcación Fiscal & Vecinos & Servicio 1528 & Maravedis Vecino \\
\hline ciudad de Segovia & 2.859 & 345.680 & 121,29 \\
sesmo del Espinar & 668 & 228.360 & 341,85 \\
sesmo de San Martin & 1.911 & 377.620 & 197,60 \\
sesmo de Las Cabezas & 1.084 & 265.400 & 244,83 \\
sesmo de La Trinidad & 786 & 136.000 & 173,02 \\
sesmo de Santaolalla & 653 & 209.440 & 320,73 \\
sesmo de Posaderas & 1.098 & 221.300 & 201,54 \\
sesmo de San Lorente & 465 & 118.020 & 253,80 \\
sesmo de San Millán & 1.309 & 166.480 & 127,18 \\
sesmo de Lozoya & 1.255 & 201.420 & 160,49 \\
sesmo de Casarrubios & 2.829 & 283.980 & 100,38 \\
sesmo de Valdemoro & 1.836 & 247.540 & 134,82 \\
\hline
\end{tabular}

En definitiva, de los once sesmos que componían la tierra de Segovia diez tenían un coeficiente maravedies/pechero superior al de la ciudad que efectuaba el repartimiento. La única excepción lo constituía el sesmo de Casarrubios, aunque la explicación de esa anomalía es sencilla: la mayor parte de las localidades pertenecían a la condesa de Chinchón, y es una realidad comprobada que, salvo excepción, los lugares de señorío tuviesen coeficientes inferiores a los de realengo. De hecho, en el sesmo de Valdemoro (jurisdicción también de la condesa de Chinchón) los pesquisidores realizaron la propuesta de repartimiento "por menudo" con el objeto de evitar los agravios y los abusos que sufrían algunas villas ${ }^{70}$.

70 No obstante las precauciones tomadas por los pesquisidores las desigualdades subsistieron dentro de este sesmo:

\begin{tabular}{lccc}
\hline Localidad & Vecinos & Propuesta repartimiento & Coeficiente \\
\hline Chinchón & 642 & 98.000 & 152.64 \\
Valdelaguna & 71 & 10.000 & 140.84 \\
Villaconejos & 65 & 7.500 & 115,38 \\
Bayona (Titulcia) & 60 & 9.000 & 150,00 \\
Ciempozuelos & 484 & 75.000 & 154,95 \\
San Martin de la Vega & 287 & 44.000 & 153,31 \\
Seseña & 237 & 33.520 & 141,43 \\
\hline
\end{tabular}


En Alcaraz, un señorío concejil ${ }^{71}$, la ciudad cabecera efectuaba frecuentes agravios sobre las aldeas de su jurisdicción; lo más frecuente era que les distribuyera un tercio del repartimiento, cuando era evidente que los pecheros de la tierra eran en su mayoria pobres; además, dentro de la ciudad el servicio se pagaba con cargo a los propios municipales ${ }^{72}$; por si ello no fuera suficiente, las autoridades de la ciudad protegían a los vecinos ricos de la tierra estableciendo una cáñama máxima de 60.000 maravedies.

El análisis de los coeficientes de otros partidos no hace sino confirmar lo hasta ahora señalado; en la provincia de Castilla de la orden de Santiago (partido de Ocaña) la ciudad presentaba hacia 1528 un coeficiente de 73,59 maravedies por pechero, algo inferior a los de sus jurisdicciones: el partido de la Ribera del Tajo $(85,35)$ y el partido de La Mancha $(88,80)$; en la extensa jurisdicción de Talavera de la Reina, la ciudad repartía 64,17 maravedíes, en tanto en su extensa jurisdicción la media se elevaba a 77,42 . En otros partidos (caso, por ejemplo, de Toro y su tierra y Zamora y su tierra) los coeficientes son prácticamente análogos entre el mundo urbano y el rural; ahora bien, hay que sospechar que tal «igualitarismo" era ficticio en función de la existencia de haciendas superiores en las ciudades.

Ante esta realidad, la propuesta de la real hacienda fue intentar adscribir a cada localidad un repartimiento preciso con el objeto de evitar los abusos de las oligarquías de los grandes núcleos. Este criterio fue suscrito por jurisdicciones como Aza, Cuéllar, la tierra de Pedraza, los lugares dependientes de Campo de Criptana, la tierra de Sepúlveda ${ }^{73}$, así como algunas jurisdicciones señoriales andaluzas (estados del duque de Medinasidonia) entre otras muchas.

\section{CONTROL DE LOS SISTEMAS DE PAGO: EL RECURSO A LOS PROPIOS Y A LA SISA}

Aunque en teoría el servicio era una carga tributaria de naturaleza directa matizada por la capacidad patrimonial de cada individuo, en realidad primó el principio de recaudar dinero sin importar los medios empleados por

"La ciudad de Alcaraz, como señora, reparte a los lugares de la tierra".

Averiguación, partido de Alcaraz.

Esta jurisdicción tiscal constituye uno de los casos documentados más expresivos de los abusos de las oligarquias dirigentes. La ciudad sólo pagaba $1 / 16$ del repartimiento, en tanto el resto (15/16) se cargaba a la tierra. Ello se debia a que las autoridades de Sepúlveda repartían siguiendo un padrón conscientemente anticuado ("seguian un libro de vecindad antiguo, por donde, como dicho es, algunos ochavos [sesmos] recibian agravio"). 
encima de cualquier criterio de equidad contributiva; el resultado fue que la real hacienda (acuciada por el gasto y la deuda) entregó la gestión de los servicios a las oligarquías locales, en tanto éstas garantizaban la puntual entrega de las cantidades repartidas. A cambio la monarquía habilitó a las autoridades municipales a que utilizaran los medios que creyesen oportunos para garantizar la percepción del tributo. El corolario de todo ello es obvio: la oligarquía utilizó los sistemas de pago en función de sus intereses.

Ello explica el frecuente recurso a los propios concejiles y al sistema de sisa para el pago de los servicios; ambos sistemas ofrecían evidentes ventajas en la eficacia recaudadora, escaso quebranto político para los grupos dirigentes y, salvo excepción, adhesión de las pecherías; en efecto, la transformación de la imposición directa en indirecta facilitaba el cobro, atemperaba las tensiones sociales cotidianas (no era lo mismo exigir un impuesto sobre el consumo que requerir personalmente a cada pechero el pago directo ante la autoridad municipal) y, sobre todo, desde la perspectiva de la oligarquía, eran sistemas que no perjudicaban sus rentas y patrimonios personales.

No es por ello casual que por toda Castilla el sistema de recurso a los propios se encontrase generalizado. Ya hemos señalado el caso de Valladolid y gran parte de las localidades de su provincia, al que cabría añadir entre otros muchos los de Ciudad Real, provincia de Soria, Alcaraz, etc. con carácter general. Si profundizamos en este tema a través de análisis monográficos de algunas provincias, los resultados aún son más espectaculares; en el caso del partido de la Mesa Arzobispal de Toledo podemos afirmar que más del 40 por ciento del servicio se recaudaba a partir de los propios; de esta manera pagaban, de manera documentalmente probada, Talavera de la Reina, Alcalá de Henares, Lillo, Yepes y Talamanca y su tierra («de sus propios paga el servicio y todos los demás pechos y tributos, sin repartir por vecinos cosa alguna") ${ }^{74}$.

Aún más generalizado se encontraba el sistema de recurrir a la sisa. Además de todos las ventajas reseñadas, la sisa aportaba algo más a los intereses de la oligarquía: se convertía fácilmente en una renta sometida a arrendamiento y proporcionaba ingresos suplementarios para las haciendas concejiles, por la tendencia a recaudar por encima de la cantidad requerida para el pago del servicio; por otra parte, en las grandes ciudades mercantiles, una parte importante de la sisa era pagada por

\footnotetext{
${ }^{74}$ Averiguación, partido de la Mesa Arzobispal, adiciones de Talavera de la Reina. En el caso de Alcalá de Henares se decia significativamente: "pagan de propios de concejo los maravedies del servicio que deben pagar lo que les está asentado a cada uno en particular".
} 
los forasteros ${ }^{75}$. Además, se podía obviar su pago alegando privilegio ${ }^{76}$, situando a paniaguados en la percepción ${ }^{77}$, o bien simplemente utilizando el poder político como argumento para no pagar ${ }^{78}$.

El problema de la sisa es que a la larga llegaba a constituir una pesadísima carga para las pecherías, ya que se tendió a recaudar por encima del cupo establecido para hacer frente al servicio. Fueron, pues, muy frecuentes las quejas sobre tales excesos: "comen los bastimentos con excesiva careza y los vecinos, así pobres como ricos, reciben notorio agravio y daño, mayormente que so color de los dichos servicios se presume que se cobra en las dichas imposiciones y sisas muchas más cantidades de lo que el dicho servicio monta" ${ }^{79}$. En realidad, los únicos beneficiarios de estas "sobras" eran las propias autoridades municipales ${ }^{80}$. ¿Podemos evaluar los incrementos impositivos producidos por el recurso a la sisa? Existe un magnífico informe ${ }^{81}$ sobre las sisas impuestas en Córdoba para el pago del servicio que nos ahorra cualquier otro comentario, y del que reproducimos ahora un avance en apretada síntesis (las cantidades van, lógicamente, expresadas en maravedies):

\begin{tabular}{lccc}
\hline Año & Valor servicio & Valor de las sisas & Exceso recaudado \\
\hline 1522 & 900.000 & 1.222 .129 & 308.629 \\
1524 & 750.000 & 1.392 .736 & 642.736 \\
1525 & 619.000 & 1.421 .376 & 802.376 \\
\hline
\end{tabular}

\footnotetext{
75 "... en la ciudad de Sevilla se echa sisa en la carne lo que les es repartido para la paga del servicio... en la antedicha sisa contribuyen todos los forasteros que van a ella, los cuales, asimismo, pagan el dicho servicio en los lugares donde son vecinos, y de ello reciben agravio".

${ }_{76}$ Caso, entre otros muchos, de Madrid: «En algunos lugares de la dicha provincia se paga el servicio de sisa, que se echa en los mantenimientos que se venden a los vecinos de tal pueblo... y en la tal [sisa] no contribuyen los que se dicen exentos y naturales del tal lugar".

Averiguación, provincia de Sevilla. En la ciudad los poderosos daban salarios a las personas que entendian en la cobranza de la sisa.

${ }_{78}$ En Murcia, donde se pagaba por sisa sobre la carne, pescado y otros productos, los regidores y jurados daban cédulas a sus criados para la compra de dichos productos sin pagar sisa. Igual sucedia en Zamora, donde los regidores. oficiales y sus correspondientes familias tampoco pagaban sisa.

79 Averiguación, provincia de Murcia. De igual manera en Sevilla, donde se denunció que los receptores de la sisa aumentaban su montante y siempre se percibía mucho más que lo que suponía el servicio. En el caso de Valladolid (véase la documentación municipal antes citada) se indicaba que con las sobras de los encabezamientos alcabalas y las sisas se comprasen juros y censos para pagar los futuros servicios.

${ }_{80}$ lbidem, "...se gastan en pleitos y otras cosas a discreción y albedrio de los oficiales del concejo, y en salarios, y ayudas de costa y otras cosas y gastos que ellos quieren y les parece...".

81 A.G.S., Consejo Real, leg. 58, expte. 7. Es una documentación muy interesante que, junto a otra de características similares, estamos estudiando en la actualidad.
} 
Esto es, en 1525 las sobras de la sisa sobre vino, pescado, jabón, aceite, heredades, etc. supusieron una cantidad mayor que el repartimiento mismo del servicio. No debe, pues, llamar la atención el gran número de advertencias lanzadas por los pesquisidores de la real hacienda contra los males de la sisa. Más aún: fue muy frecuente que estos mismos delegados de la contaduría propusieran que los concejos, caso de contar con saneados ingresos en sus haciendas, sustituyeran las sisas por el recurso a los propios: "tienen rentas y propios de concejos... en cantidad que podrían pagar los maravedíes que les caben del servicio de su majestad, sin repartir nada por los vecinos, ni poner imposición de sisa como para ello las ponen» ${ }^{82}$.

\section{RESISTENCIAS A LAS PRÁCTICAS DE LA OLIGARQUIAA}

Uno de los aspectos de los que, por ahora, tenemos menos información es el referido a las reacciones que suscitaron tales prácticas abusivas y corruptas. No obstante, un primer análisis - todavía en estudio- de la documentación contenida en los pleitos ante el Consejo Real, la contaduría mayor y otras instancias judiciales de la monarquía aconsejan pensar que pronto podamos disponer de un panorama más halagüeño.

En cualquier caso, hemos de partir de un hecho que se nos antoja incuestionable: la violencia, en toda su jerarquía de manifestaciones (desde una simple protesta o queja hasta el asesinato), fue algo consustancial con la misma existencia de cualquier organización oligárquica. En efecto, en el tema que nos ocupa, fue muy frecuente que los pecheros denunciaran los abusos y corruptelas de las oligarquías locales, bien de manera oral, bien por escrito anónimo ante alguna autoridad central. De hecho, los informes realizados por los pesquisidores están inundados de protestas de los pecheros y de relatos de fuerzas ejercidas por los poderosos.

No cabe duda que las pecherias tenían miedo de las represalias que podian sufrir si manifestaban y denunciaban las prácticas de los regidores y oligarcas. Y ello no es una conjetura o suposición lógica fruto del sentido común de cualquier historiador; lo afirma la propia documentación generada por los servicios de Cortes. En Asturias, por ejemplo, los pesquisidores propusieron que el reparto y percepción de los servicios fuesen controlados por las justicias, toda vez que se habia comprobado que las autoridades lo-

82 Este informe hacia especial referencia a los concejos de Murcia, Cartagena, Lorca, Chinchilla, Mula, etc. de la provincia de Murcia. 
cales obraban a su antojo después de amedrentar a los pecheros para que no les denunciaran ${ }^{83}$.

Sin embargo, cuando el miedo y el temor eran superados por algunos pecheros las oligarquías no dudaron en apelar a la violencia extrema, llegándose incluso al asesinato de los que se atrevían a denunciarlos ante ciertas instancias judiciales. Un ejemplo de esta violencia extrema de las oligarquías consta en el informe de los pesquisidores que visitaron la ciudad de Zamora; una localidad, como hemos indicado, donde la oligarquía era particularmente agresiva en defensa de las familias pecheras vinculadas con el gobierno municipal y los poderosos:

"Asimismo, los que viven con los dichos regidores y con otros caballeros..., aunque sean pecheros y tengan casa, mujer e hijos en la dicha ciudad no pagan en el dicho servicio, ni los dichos regidores y caballeros se lo consienten cobrar, y si en ello insisten acuerdan dar cuchilladas a los que seguían el pleito, molestándoles por todas las vías y muerto uno o dos que seguían cierto pleito contra los susodichos" ${ }^{84}$.

4* Averiguación, partido de las Asturias de Oviedo, "Cuando se repartiesen los maravedies del servicio debian estar presentes las justicias con los repartidores de él para les quitar el temor que las tales personas les ponen", y más adelante se dice: "y los otros pecheros no se osan quejar de ello por temor de las tales personas".

84 Averiguación, provincia de Zamora, adiciones, edeclaración y juramento de los que hicieron los padrones de la dicha ciudad". 